\title{
Looking for inhibition of return in pigeons
}

\author{
BRETT M. GIBSON, IGOR JURICEVIC, SARA J. SHETTLEWORTH, and JAY PRATT \\ University of Toronto, Toronto, Ontario, Canada \\ and \\ RAYMOND M. KLEIN \\ Dalhousie University, Halifax, Nova Scotia, Canada
}

\begin{abstract}
We conducted four experiments in order to investigate whether pigeons' responses to a recently attended (i.e., recently pecked) location are inhibited. In Experiments 1 and 2, stimulus displays were similar to those used in studies of inhibition of return (IOR) with humans; responses to cued targets tended to be facilitated rather than inhibited. In Experiments 3 and 4, birds were presented with stimulus displays that mimicked clusters of small grains and were relatively localized, which should have been more appropriate for detecting IOR in pigeons. The results from these experiments again provided evidence for facilitation of responding to cued targets, rather than for IOR.
\end{abstract}

Inhibition of return (IOR) refers to the finding that targets presented at previously attended locations are responded to more slowly than are targets presented at unattended (i.e., novel) locations (Posner, Rafal, Choate, \& Vaughan, 1985; see Klein, 2000, for a review). In the typical IOR experiment, the abrupt appearance of a new object in the periphery (the cue) is used to capture attention in the periphery of the visual field before the object that the subject must respond to (the target) appears. The effect of the cue is usually biphasic. At short delays between the cue and the target (stimulus onset asynchrony, SOA), response times (RTs) are typically shorter for targets that appear at cued locations than for targets that appear at noncued locations. That is, responses are facilitated at the cued location. However, at longer cue-target SOAs, RTs are longer for targets that appear at the cued location and shorter for targets that appear at a noncued location. In this case, responses are inhibited at the cued location, and this inhibitory effect has become known as IOR.

IOR has proven to be a very robust phenomenon in studies in which human subjects have been used. For example, it occurs both in detection tasks - that is, when subjects respond to the appearance of a target (see, e.g., Posner $\&$ Cohen, 1984) - and in various types of discrimination tasks, when subjects respond to some feature of a target (see, e.g., Pratt, Kingstone, \& Khoe, 1997). The inhibitory effect is largely insensitive to the mode of response. IOR has been found with keypress responses (e.g., Posner \& Cohen, 1984), computer mouse pointing responses (e.g.,

This study was supported by a research grant to S.J.S. from the Natural Sciences and Engineering Research Council of Canada. We thank Jennifer Barker and Noam Miller for their assistance with this project, as well as David Kabelik, who developed the stimuli that were used in Experiments 3 and 4. Correspondence concerning this article should be addressed to B. M. Gibson, Department of Psychology, University of New Hampshire, Conant Hall, Durham, NH 03824 (e-mail: bgibson@ cisunix.unh.edu)
Briand, Larrison, \& Sereno, 2000), manual pointing responses (e.g., Fischer, Pratt, \& Neggers, 2003), and saccadic responses (e.g., Taylor \& Klein, 2000). Although IOR is typically tested with college-aged adults, there is also evidence that infants (e.g., Clohessy, Posner, Rothbart, \& Vecera, 1991), children (MacPherson, Klein, \& Moore, 2003), and elderly adults (e.g., Castel, Chasteen, Scialfa, \& Pratt, 2003; Hartley \& Kieley, 1995) show IOR. Thus, in experimental situations in which peripheral cues precede visual targets by relatively long SOAs (>300 msec), IOR is a very robust effect.

IOR was first hypothesized to function as a foraging facilitator by Klein (1988). Recently, converging evidence supporting this proposal has been reported by Gilchrist and Harvey (2000) and Klein and MacInnes (1999). To be more specific, IOR improves the efficiency of searching for visual targets by discouraging both overt and covert reorienting to a previously cued object or location. Klein and MacInnes found increased saccadic RTs for targets that appeared in the general region of a previous fixation. They also found, prior to the appearance of the target, a strong directional bias away from previously fixated regions. MacInnes and Klein (2003) argued that the latter bias was caused by inhibition of responses to the previously fixated locations. Whether or not this is the case, both of these effects increase the chances that unvisited locations will be visually searched before recently visited locations are returned to. As compared with a random search, this would reduce the number of eye movements made, thereby increasing efficiency when there is an attempt to search all locations. Similar effects have been hypothesized to occur in visual searches that involve shifts of attention without corresponding eye movements (e.g., Kingstone \& Pratt, 1999; Snyder \& Kingstone, 2000).

Several factors might increase the potential benefits of IOR in foraging for food. For example, food search rates may be fast although food production is slow. In this case, once the food at a visited location has been consumed, the 
time it will take for food to be available there once again may be much longer than the time required for searching many other locations. Even if no food has been found at a location, it is still likely that many other locations can be searched before food becomes available at the current location. This would appear to be the case for animals that use visual search to forage for slowly repleting sessile food items, such as seeds. However, although IOR in humans has been explored in a large body of work, IOR in other animals has been tested for in relatively few studies.

One notable exception can be seen in recent studies in which IOR-like effects have been tested for with monkeys. Dorris, Taylor, Klein, and Munoz (1999) trained monkeys to attend to a central fixation stimulus while a cue appeared either to the left or to the right of the fixation stimulus. The cue disappeared, and then, when the fixation stimulus was removed, reappeared either at the same location or at a location that was opposite or diagonal to the original target in a matrix of possible target locations. The monkey was then required to make a saccade to the target, following the disappearance of the fixation stimulus. During this stimulus-saccade task, the monkey's saccadic RTs were longer to the final target when the target occupied the same location across both phases of the trial than when the final target appeared at a different location. These results are similar to the effect of IOR reported for humans, as described previously. In a follow-up study, Dorris, Klein, and Everling (2002) used single-unit recording and electrically evoked saccades to study the involvement of neurons in the superior colliculus during performance of their task.

If, as was suggested by Klein (1988), IOR evolved to facilitate efficient foraging, many species, in addition to humans and nonhuman primates, might be expected to display IOR-like effects. Indeed, there is reason to think that many attentional phenomena are general across species. Clark and Dukas (2003) have recently constructed an optimality model based on the attentional demands placed on animals that forage for cryptic food while, simultaneously, being faced with the detecting of predators. Their model indicates that limited attention may be a solution for the processing of large amounts of information by animals and may limit the costs of building and maintaining brain tissue. Perhaps IOR also serves as a way in which animals balance these needs.

Here, we will report four tests for IOR in pigeons. Pigeons eat mainly grains and seeds, which they detect visually (Zeigler, Jäger, \& Palacios, 1993). Because grains are largely immobile and do not replete immediately, reinspecting locations too soon would likely be inefficient, suggesting that IOR during search may be apparent. Furthermore, extensive studies of the processes involved in visual search in pigeons have revealed many of the same attentional phenomena as those found in humans. These include the dividing of attention, set size effects on visual detection, and priming (D. S. Blough \& P. M. Blough, 1997; Kelly \& Cook, 2003; Riley \& Roitblat, 1978; see
Shettleworth, 1998, for a review). Thus, it seems likely that the similarities in visual and attentional processing between pigeons and humans may extend to IOR.

In Experiments 1 and 2, we used displays similar to those used with people when there were comparatively large (2-cm diameter) target items located around the periphery of the computer monitor. The effect of a recently presented peripheral cue was investigated by giving pigeons a choice between two identical search targets, one of which appeared in the same location as the peripheral cue. This method is similar to that used by researchers investigating IOR by humans (e.g., Clohessy et al., 1991). In Experiments 3 and 4, we employed displays more like those used in previous laboratory studies of attentional mechanisms and visual search in pigeons (D. S. Blough \& P. M. Blough, 1997; Langley, Riley, Bond, \& Goel, 1996). Clusters of small, grain-like items appeared at various locations around the screen, and possible IOR effects were measured in terms of RTs for the pecking of a target item.

\section{EXPERIMENT 1}

\section{Method}

Animals. Six adult 3.5- to 5.5-year-old White King pigeons originally obtained from Palmetto Pigeon Plant (Sumter, SC) served in this experiment. Three of the pigeons had previous experience in operant experiments, not including tests of IOR, whereas the other 3 were experimentally naive. The pigeons were individually housed in $38 \times 48 \times 55 \mathrm{~cm}$ wire mesh cages in a room that was kept on a 14:10-h light:dark cycle. The pigeons were maintained at $85 \% \pm$ $2 \%$ of their ad lib body weight, with controlled feedings of mixed grain following each daily experimental session. All the pigeons had ad lib access to water and grit.

Apparatus. The operant chambers were constructed from translucent Plexiglas and were $40.5 \mathrm{~cm}$ high $\times 30.0 \mathrm{~cm}$ wide $\times$ $29.0 \mathrm{~cm}$ long. The front wall of the chamber opened onto a 14-in. flat screen computer monitor. The base of the monitor screen was $11.5 \mathrm{~cm}$ above the floor. A $19.0 \times 26.5 \mathrm{~cm}$ touchscreen frame (Carroll Touch, Round Rock, TX) surrounded the computer monitor. The touchscreen projected a grid of infrared beams across the surface of the monitor. Pecks made by a pigeon to the stimuli presented on the computer monitor "broke" one or more of the infrared beams, and the Cartesian position and time of the peck could be recorded. A sheet of unreflective Plexiglas covered the monitor screen. Noyes Pigeon Pellets $(20 \mathrm{mg})$ could be released from a feeder located outside the chamber into a food tray, $18.5 \times 5 \times 1 \mathrm{~cm}$, that was located $6 \mathrm{~cm}$ above the floor of the chamber just below the monitor. A white light in the ceiling of the operant chamber illuminated the food tray when pellets were delivered; otherwise, the room was dark. A computer in the adjoining room controlled and recorded the session events

Training. Each naive pigeon was initially shaped, using the procedures of successive approximation, to peck at stimuli on the computer screen. The pigeons were gradually introduced to training trials that contained multiple steps. Each training trial began when a red fixation stimulus (3-cm-diameter disk) appeared in the center of the screen. Eight white unfilled squares $(3.2 \mathrm{~cm}$ on a side) also appeared on a perimeter around the fixation stimulus; the background of the screen was gray (see Display 1 in Figure 1 for an example). The squares were spaced by $45^{\circ}$ evenly around the fixation stimulus; the center of each square was $15.2 \mathrm{~cm}$ from the center of the fixation stimulus. The squares outlined eight locations on the screen in which 


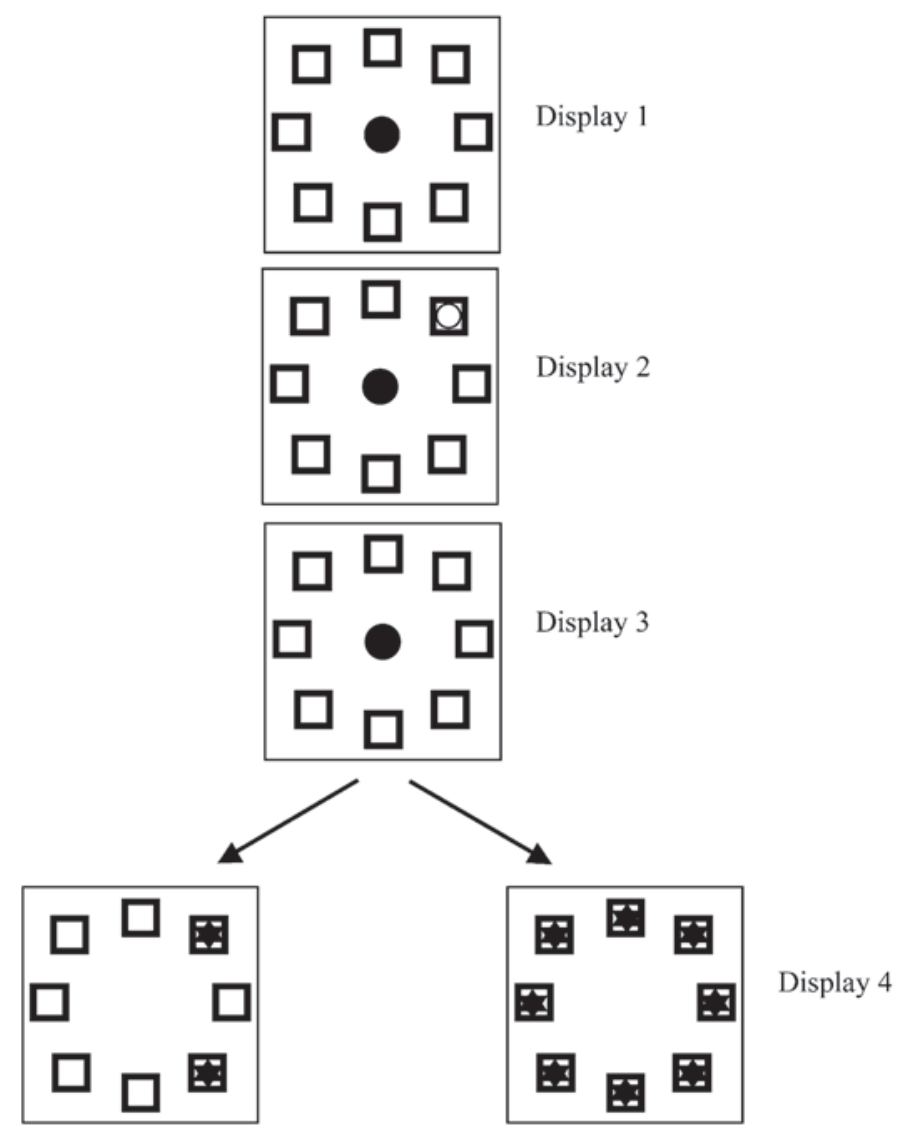

Figure 1. Sequence of stimulus events during a testing trial in Experiments 1 and 2. The edge of the computer monitor is indicated by the large box around each stimulus display. The filled circle in the center of a display indicates the appearance of the fixation stimulus, whereas an unfilled circle (second frame) depicts the cue. The eight smaller unfilled squares in each display indicate the potential locations where the cue and target could be positioned during testing (see the Method section in Experiment 1). The first three displays were identical for Experiments 1 and 2. However, during Experiment 1, two cues were presented in the fourth display (Display 4, left), but all eight potential target locations were filled during the presentation of the fourth display during Experiment 2 (Display 4, right).

either a cue or a target could appear. A response to the central fixation stimulus resulted in a 3-cm-diameter white disk (the cue) immediately appearing inside one of the eight squares, randomly selected. A peck to the cue immediately cleared it from the screen. Following a second peck to the fixation stimulus, a 3-cm-diameter green star that served as a target immediately appeared inside a square at one of the eight locations. The target location was randomly selected across trials so that, regardless of the cue, each of the eight locations was equally likely to contain the target. A single peck to the target inside the square was followed by the delivery of three pellets and illumination of the feeder light for $6 \mathrm{sec}$. Pecks delivered to empty squares resulted in the monitor screen's being darkened for $60 \mathrm{sec}$. A new trial began immediately after the conclusion of the current trial. Seven sessions of 224 training trials had to be completed, and the average RT to the target had to be less than $750 \mathrm{msec}$ for the last three consecutive sessions before a bird advanced to testing.

Testing. The sequence of events during the testing trials was identical to that during training, except that following the second response to the fixation stimulus, which removed this stimulus from the screen, two targets immediately appeared, one at each of two of the eight locations (see Figure 1). A target at the location at which the cue had been positioned was defined as the cued target, whereas a target that appeared at a location other than the cued position was defined as a noncued target. A peck to either one of the two targets was followed immediately by the darkening of the monitor and the delivery of three pellets. A peck at an empty square during this final part of the trial darkened the screen for $60 \mathrm{sec}$. No time limit was placed on responding during any part of the trial. Once an entire trial had been completed (including the $6 \mathrm{sec}$ following reinforcement or the 60 -sec punishment delay), the next trial began. Target choice (cued or noncued) and the time it took the birds to select a target (in milliseconds) were recorded.

There were 28 unique combinations of the two target locations (i.e., $7+6+5+4+3+2+1$ ) that could be occupied during testing (e.g., targets might be found in the southeast and northwest squares during one trial $\left[180^{\circ}\right.$ apart $]$ and in the east and southeast squares [ $45^{\circ}$ apart] during another, representing 2 of the 28 unique two-target combinations). Each combination occurred the same 
number of times with each of the eight cue locations during the course of a session, so that the cue location could not be predictive of the location of a target. Factorially combining these 28 two-target possibilities with the eight potential cue locations resulted in 224 trials being conducted during each daily session. The location of the target was cued during 56 of the 224 trials. The remaining 178 trials were not cued, because the location of both targets during the choice phase was different from that of the cue. However, a cue appeared in every trial in the present experiment, as is typical in many IOR studies with humans. Each bird completed 20 sessions of testing during Experiment 1.

Analysis. Only the data from the trials in which the target was cued were used in the analyses described below. For the analyses in which the choice measure was used, we determined the number of times that the birds selected the cued and noncued targets during testing. Choices then were grouped in terms of the degree of separation between the locations of the cued and the noncued targets on a given trial, regardless of the absolute locations of the two targets. Specifically, the noncued target could be one, two, three, or four locations away and could be positioned either clockwise or counterclockwise from the cued target (Figure 1). Positive integers $(+1,+2,+3,+4)$ were used to indicate that the cued target was clockwise from the noncued target $(+4$ when the noncued target was $180^{\circ}$ away from the cued target), whereas negative integers $(-1$, $-2,-3)$ were used to indicate that the cued target was counterclockwise from the noncued target.

Because the choice response variable had a binary distribution, we used generalized linear interactive modeling (GLIM; Numerical Algorithms Group, Downers Grove, IL) to fit a log-linear model to the data (Francis, Green, \& Payne, 1993). The log-linear model produced by GLIM specified a binomial error term, as opposed to another type of distribution (e.g., normal distribution). The GLIM model then was used to examine for reliable relationships among the explanatory variables (e.g., target separation) and the response measure (choice). The test statistic that GLIM used to examine these effects was then compared with a chi-squared distribution (note that this is not a chi-square test of independence). Thus, GLIM allows ANOVA-like tests to be performed but is more appropriate for binary choice data. GLIM also was used to assess whether choice proportions were significantly above chance. Alpha was set at .05 for the determination of significant effects.

Two sets of analyses with GLIM were conducted. The first analysis used GLIM to examine whether the pigeons had a preference for either the cued or the noncued target and how choice of these targets changed as the separation between the cued and the noncued targets increased. This analysis used target type (cued or noncued) and target separation $(-3,-2,-1,+1,+2,+3$, or +4$)$ as factors. Follow-up GLIM comparisons examined whether choices for the cued and the noncued targets were reliably different from each other for each level of target separation. A second GLIM analysis examined whether the number of choices for the cued and noncued targets was different from that expected by chance. GLIM was also used to examine whether the proportion of choices for cued and noncued targets differed from chance for each level of the target separation factor. IOR-like effects would be observed if the birds reliably selected the noncued target more frequently than the cued target, especially as the separation between the two targets increased.

We performed a second set of analyses in which RT was used as a measure. The RT data were prepared for analysis with procedures that had previously been described for pigeons (e.g., P. M. Blough, 1991). Specifically, median RT scores were determined for each session for each level of the target type and target separation factors. RTs that exceeded $4 \mathrm{sec}$ were excluded from the median calculation; less than $1 \%$ of the data was excluded as outliers. The median RT scores were log transformed to maintain normality. A within-subjects ANOVA then was conducted that used target type and target separation as repeated factors and average median RT as the dependent measure. IOR-like effects would be observed if the birds responded more quickly to the noncued target than to the cued target, especially as the separation between the cued and the noncued targets increased.

\section{Results}

As can be seen in Figure 2, the birds selected the cued target more frequently than the noncued target for five of the seven levels of target separation $(-3,+1,+2,+3$, and +4$)$. GLIM revealed a reliable main effect of target type $\left[\chi^{2}(1)=8.179\right]$. The birds tended to select the cued target when the noncued target was located one position clockwise from the cued target and to select the noncued target when the latter was located counterclockwise from the cued position. Accordingly, GLIM revealed a reliable interaction between target type and target separation factors $\left[\chi^{2}(6)=101.2\right]$. The birds selected the cued target on reliably more occasions than the noncued target when the noncued target was located $+1,+2,+3$, and +4 positions clockwise from the position of the cued target but selected the noncued target more frequently than the cued target when the noncued target was located -1 position from the cued location. GLIM failed to indicate a main effect of target separation $\left[\chi^{2}(1)<1\right]$, as was expected. The second GLIM analysis indicated that choice of the cued target, collapsed across all levels of target separation, was not significantly above chance $\left[\chi^{2}(1)=1.615\right]$. Subsequent GLIM comparisons indicated that choice for the cued target was reliably above chance when the noncued target was located one position clockwise $(+1)$ from the cued location $\left[\chi^{2}(1)=9.268\right]$, however. Choice for the cued target was reliably below chance when the noncued target was located one position counterclockwise $(-1)$ from the cued location $\left[\chi^{2}(1)=13.46\right]$. The pigeons responded more quickly to the cued target than to the noncued target for five of the seven levels $(-3,-1,+1,+2$, and +3 ) of target separation (see Figure 2). An ANOVA indicated a reliable main effect of target type $[F(1,5)=$ 14.45]. The analysis failed to reveal a reliable effect of target separation $[F(6,30)=1.90]$ or an interaction between target type and target separation $[F(6,30)<1]$. The average SOA - that is, the time between the onsets of the cue and the target-was $1,590 \mathrm{msec}(S E M=110)$.

\section{Discussion}

The analyses of both the choice and the RT measures indicated that responses to a target that had been cued were facilitated, as compared with responses to a target that had not been cued, regardless of the degree of separation between the two targets. Responding was facilitated particularly when the noncued target was located clockwise from the cued location. Such an effect, although difficult to explain, could not reflect a bias toward responding to specific target locations, since the targets were located equally often at all possible positions during testing.

The results of this experiment failed to provide any evidence for IOR. IOR-like effects would have been 

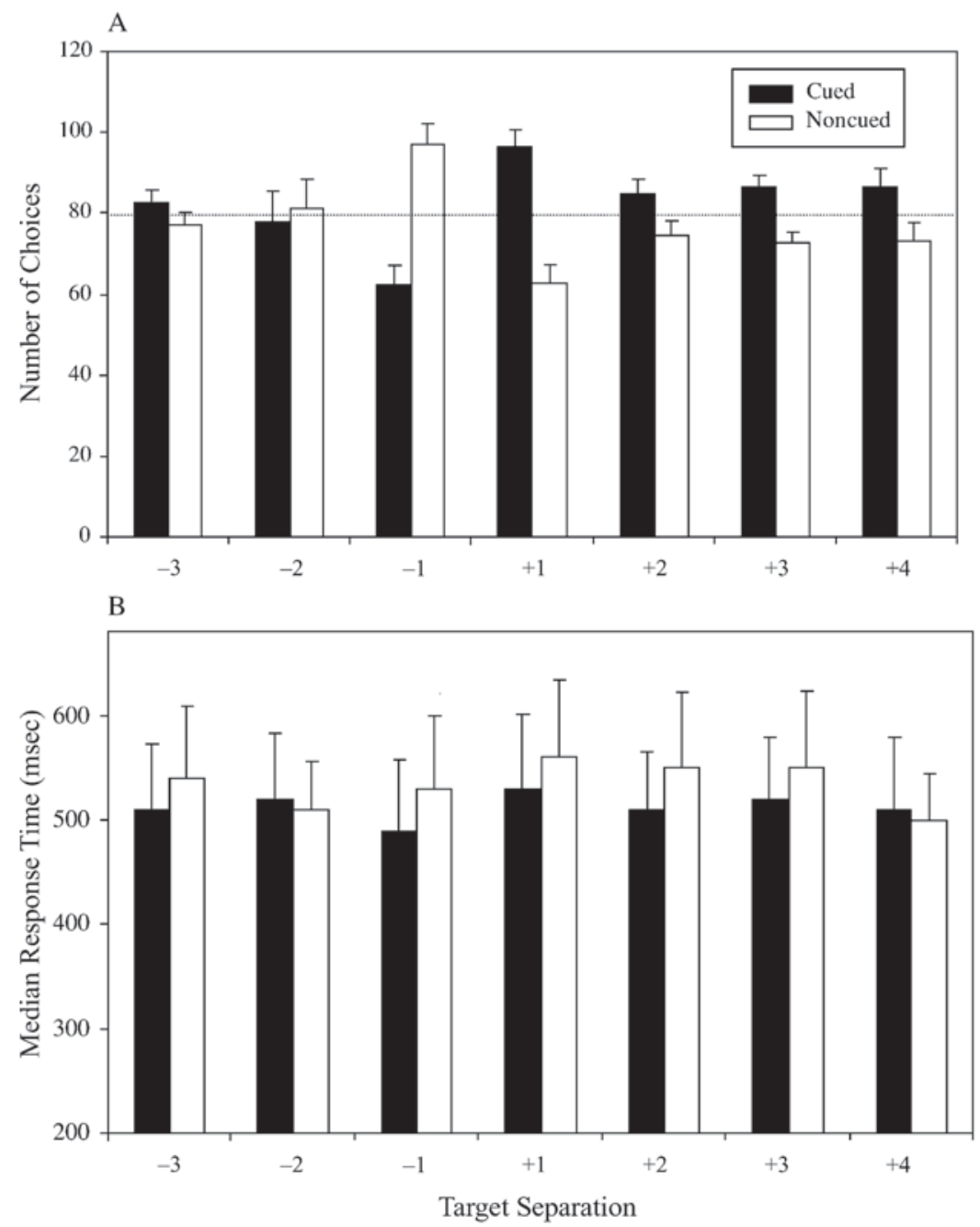

Figure 2. (A) Mean number of times the pigeons selected the cued and noncued targets for each level of target separation $(-3,-2,-1,+1,+2,+3$, and +4$)$ during Experiment 1. Error bars reflect SEMs. The fine dashed line indicates chance levels of performance. (B) Mean median response times to cued and noncued targets for each level of target separation.

revealed if the birds had preferred or responded more quickly to the noncued target at increasing levels of target separation. McCarley, Wang, Kramer, Irwin, and Peterson (2003) found IOR-like effects with people, using procedures similar to those used in the present Experiment 1. In that study, people directed their gaze from one item on a computer screen to the next item until they encountered a target item or the trial ended. At selected points in the trial, the subjects had a choice between gazing at an item at a location that they had encountered earlier in the trial (decoy location) or at an item at a novel location. There was a strong tendency for people to shift their gaze to the novel location, as compared with the decoy location, during these choice conditions, particularly if the subjects had recently fixated at the decoy location during the trial.

The advantage of using two targets to test for IOR, as in the procedure for the present experiment and that of
McCarley et al. (2003), is that both choice and RT can be measured. Nevertheless, despite the fact that IOR has been found in people with a choice method similar to ours (McCarley et al., 2003), the two-target method may not be the most sensitive test of IOR. In most studies that have documented IOR, only one target has been presented during cued testing, and RT has been used as the dependent measure (e.g., Posner \& Cohen, 1984; Taylor \& Klein, 2000). Kingstone and Pratt (1999) found a much smaller effect of IOR in humans when the testing display consisted of a target and a distractor, rather than a target alone (see also Lupiáñez, Milliken, Solano, Weaver, \& Tipper, 2001). Therefore, in Experiment 2, we used a design that allowed us to assess the presence of IOR by using both choice and RT measures but that did not force the bird to choose between a cued target and a second, noncued target whose location was unpredictable. 


\section{EXPERIMENT 2}

Experiment 2 was similar to Experiment 1, except that a target appeared at all of the eight possible locations during the choice phase of testing. Since the relative locations of the cued target and the noncued targets were perfectly predicted and the stimulus display was exactly the same on every test trial, any effects of facilitation or IOR might be more robust.

\section{Method}

Animals and Apparatus. The subjects were the 6 pigeons that had participated in Experiment 1, maintained in the same way. The apparatus for this experiment was the same as that in Experiment 1.
Testing. The sequence of events that occurred during testing was the same as that in Experiment 1, except that a target appeared at each of the eight locations simultaneously during the choice phase (Figure 1, Display 4, right). One of the targets was a cued target, whereas the other seven targets were noncued targets. The location of the noncued targets, relative to the cued target, remained stable across trials. A response to any of the eight targets resulted in the delivery of the food reward. During each trial, we recorded the location of the target (cued or noncued) that the birds pecked during the choice phase, as well as the time it took the bird to make that choice. To keep the session length comparable to that in Experiment 1, 224 trials were given per session; a target was cued during every trial. One session was conducted per day, and testing lasted for 6 days.

Analysis. Each trial was coded, as in Experiment 1, in terms of the degree and direction of separation between the location of the cued target and the location of the selected target. The choices then

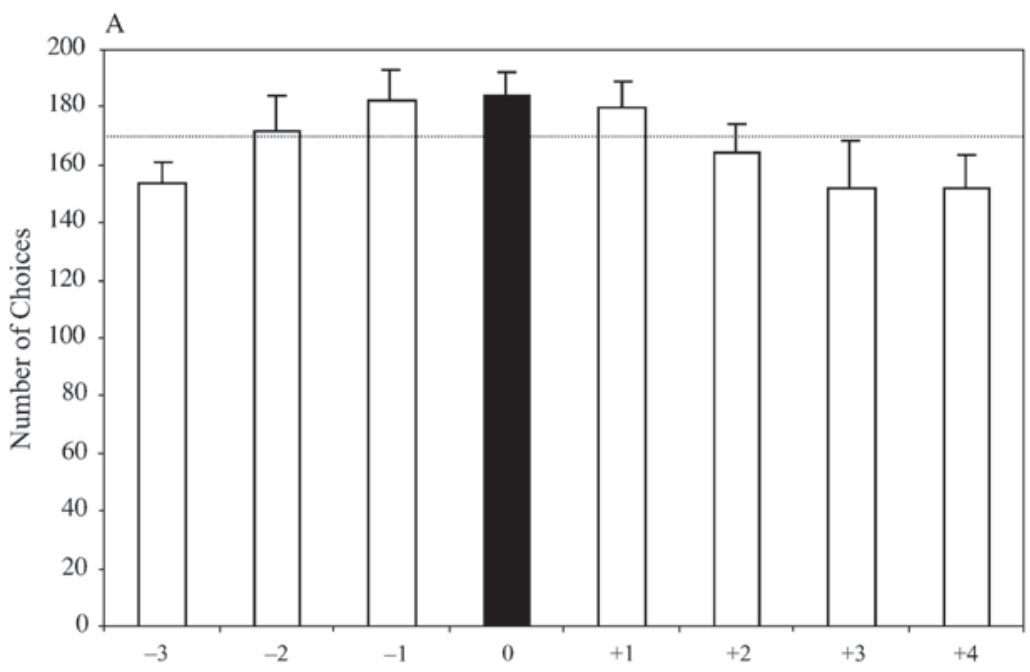

B

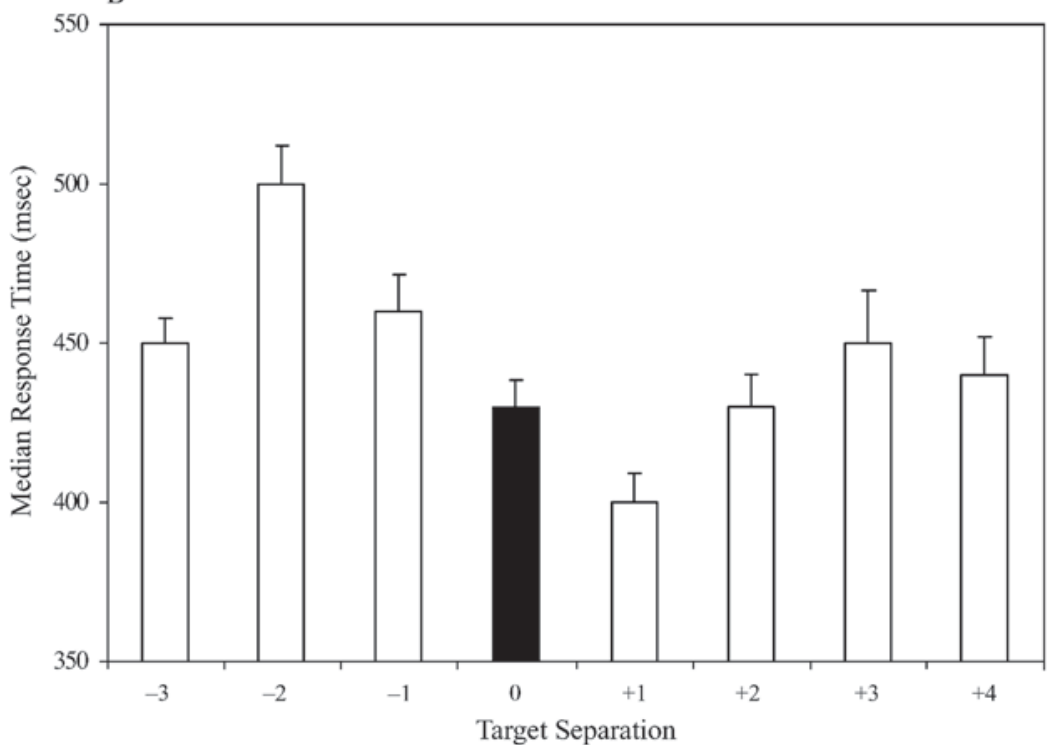

Figure 3. (A) Mean number of times the pigeons selected the cued target (solid bar; target separation $=0$ ) and noncued targets (target separation $=-3,-2,-1,+1,+2$, +3 , or +4 ) for the various levels of target separation during Experiment 2. Error bars reflect $S E M$ s. The fine dashed line indicates chance levels of performance. (B) Average median response times to cued and noncued targets for each level of target separation. 
were summed across trials and for each of the eight levels of the target separation variable $(-3,-2,-1,0,+1,+2,+3$, and +4$)$. The data from every trial were used in the analyses described below.

As in Experiment 1, two sets of analyses - using choice and RT measures, respectively - were conducted. GLIM again was used for the assessment of the choice data. An initial analysis was performed with target separation $(-3,-2,-1,0,+1,+2,+3,+4)$ as a repeated measure and choice as a dependent measure. Follow-up GLIM comparisons examined whether choices for the cued and the noncued targets were reliably different from each other. A second GLIM analysis examined whether the proportion of choices for the cued and noncued targets was different from that expected by chance. The RT data were calculated as in Experiment 1 and were grouped and summarized in accordance with target separation. A repeated measures ANOVA that used target separation as a repeated factor and RT as the dependent measure was conducted.

\section{Results}

As in Experiment 1, the birds tended to select the cued target (target separation $=0$ ) more frequently than the noncued targets, especially as the noncued target moved farther away from the position of the cued target (see Figure 3). GLIM revealed a main effect of target separation $\left[\chi^{2}(7)=47.91\right]$. There appeared to be little difference in preference for the cued target and for noncued targets that were in close proximity to the cued location $(-2,-1$, or +1$)$, however. Follow-up GLIM comparisons indicated that the birds selected the cued target (target separation $=0$ ) more frequently than the noncued targets located at positions $-3,-2,+2,+3$, or +4 . A second GLIM analysis indicated that the birds failed to select the cued target more frequently than would be expected by chance $\left[\chi^{2}(7)=4.40\right]$.

The pigeons also responded more quickly to the cued target (target separation $=0$ ) than to the noncued targets occupying five of the seven noncued locations (Figure 3). The results from the ANOVA with RT as a dependent measure indicated a reliable effect of target separation $[F(7,35)=2.70]$. Follow-up least squares comparisons indicated that responses to the cued target were faster than those to the noncued target position at location -2 $[F(1,35)=6.47]$. No other reliable differences in RTs were revealed between the cued and the noncued locations (all $p \mathrm{~s}>.05)$. The average SOA across all conditions was $1,610 \mathrm{msec}(S E M=140)$.

\section{Discussion}

The procedures in Experiment 2 were similar to those in Experiment 1, except that a target appeared at each of the eight possible locations simultaneously during the choice phase. As in Experiment 1, both the choice and the RT measures indicated facilitation of responding to the cued target, as compared with a noncued target. For both choice and RT, facilitation for the cued target was most apparent when it was compared with noncued targets that were positioned farther clockwise and counterclockwise from the location of the cue. Thus, like Experiment 1, Experiment 2 failed to reveal any evidence for IOR.

The results from Experiments 1 and 2 are also consistent with those of Dorris et al. (1999), who found that monkeys showed response facilitation to targets when a saccade-saccade paradigm was used, rather than the stimulus-saccade procedure mentioned in the introduction. Specifically, Dorris et al. (1999) trained monkeys to attend to a saccadic target that moved from a central location to a peripheral location and back to center before moving toward the same peripheral location that had been used earlier in the trial or a different peripheral location. Under these conditions, monkeys, like the pigeons in the present study, were faster to respond to the saccadic target when it returned to a peripheral position that it had previously visited than when the saccadic target occupied another peripheral position.

\section{EXPERIMENT 3}

The results from Experiments 1 and 2 are somewhat surprising, since IOR might be expected to be beneficial for pigeons as they scan a small area searching for grain. The failure of these experiments to document IOR may reflect an incompatibility between the procedures we employedprocedures that were based on work with humans - and the perceptual systems of pigeons. Although IOR may have evolved to function during foraging to inhibit returning to locations at which food had previously been found (Gilchrist \& Harvey, 2000; Klein \& MacInnes, 1999), the displays used in Experiments 1 and 2 may not require the same kind of visual search that pigeons engage in when they forage. This may be true for at least two reasons. First, unlike humans and monkeys, pigeons are bifoveal and primarily use a central, binocular visual field when detecting and pecking at grains (see Zeigler et al., 1993). This binocular field comprises the central $30^{\circ}$ of the visual field. The second fovea is located laterally in each eye and appears to be used primarily to detect predators. In Experiments 1 and 2, pigeons were required to peck a centrally located stimulus at the beginning of each trial, and, subsequently, to peck stimuli that were dispersed across a large surface. Because the binocular field seems to be critical for localizing pecking, IOR-like effects may occur when targets have been observed inside, rather than outside, this part of the visual field. Although we cannot be sure, it seems reasonable to assume that many of the targets in Experiments 1 and 2 were, instead, initially detected using the lateral fovea, because they appeared at unpredictable locations near the edge of the screen as soon as the bird had pecked at the center of the screen. Targets that are presented more locally during testing like that described in Experiment 1 may be more likely to be detected primarily by the central fovea. In turn, such tests may be more sensitive in detecting IOR in the pigeon.

A second reason why the procedures in Experiments 1 and 2 may not have detected IOR is that in the natural environment of pigeons, desirable grains are often found among other, similar-appearing and distracting items. Thus, the "target" grains may appear camouflaged against a background of similar-looking grains (e.g., Bond, 1983). The detection of target food items among distractors often requires serial, rather than parallel, search, and it is in this kind of situation that some of the best evidence 
for similarities in attention between pigeons and humans has been found (for discussions see D. S. Blough \& P. M. Blough, 1997; Reid \& Shettleworth, 1992; Shettleworth, 1998, chap. 2). In particular, there is a short-term facilitation (priming) of the detecting or choosing of items that share features such as color or shape with recently pecked items. Note, however, that this search image effect pertains to features of items other than their location. There is good evidence that IOR occurs when humans engage in serial visual search (e.g., Klein, 1988; Müller \& von Mühlenen, 2000; Takeda \& Yagi, 2000).

Experiment 3 was designed to address these issues by presenting pigeons with stimuli similar in size and color to those a pigeon might experience while foraging and by presenting them within a localized area of the computer screen. Furthermore, in an attempt to engage serial, rather than parallel, search, we presented the target stimulus in the company of distractors that differed from the target in shape or color. Thus, the final stage of each trial is more consistent with a discrimination task than with a detection task.

\section{Method}

Animals. Four experimentally naive adult White King pigeons that were 18 months old at the time of testing were used in this experiment. The birds were maintained as in Experiments 1 and 2.

Training. Training and testing were conducted in the same operant chambers and room as those used in Experiments 1 and 2. The pigeons were shaped to peck stimuli on a computer screen and were gradually introduced to the stimuli and sequence of events to be used in the training trials. Each training trial began when a fuchsia start disk (3-cm diameter) appeared in the center of the monitor. A single peck to the start disk advanced the trial. Following a 1-sec delay, a grid composed of 3 columns $\times 3$ rows (nine rectangular cells) appeared at one of 32 randomly determined locations on the computer screen (see Figure 4 for an example of the stimuli used during training and testing). The lines of the grid were bold and gray, and each cell formed by their intersection was $1(h) \times 1.5$ (w) $\mathrm{cm}$. Four stimuli appeared simultaneously in the grid and could be placed in four of the eight peripheral cells (the central cell was not used during training) according to a random schedule. One of these stimuli was the target, a yellow oval $(1 \times 0.5 \mathrm{~cm})$, or "seed." The other three distractors were a brown "seed," a yellow "peapod" composed of two vertically stacked disks $(1 \times 0.5 \mathrm{~cm})$, and a brown "peapod." The location of the target and distractors was determined randomly each trial. A peck to any of the distractors resulted in the stimuli and grid's immediately being cleared from the screen, followed by a $30-\mathrm{sec}$ timeout in which the houselight was turned off; the stimuli then reappeared in their original configuration, and the trial was repeated. A single peck to the target, in contrast, immediately cleared all four stimuli from the screen, and a light blue disk (1-cm diameter) immediately appeared in the central cell of the grid. A single peck to the blue disk cleared the disk from the screen, and the target and distractors immediately reappeared in the cells of the grid at new, randomly determined locations. A peck to the target (correct response) resulted in the houselight's being turned on for $3 \mathrm{sec}$ and six pellets being delivered, whereas a peck to any of the distractors (incorrect response) immediately cleared the screen and resulted in a 30 -sec timeout. Pecks to empty cells had no effect during the trial. A 15 -sec intertrial interval (ITI) ensued before the start of the next trial. In contrast, an incorrect response during any part of the trial resulted in the trial's being repeated until a correct response

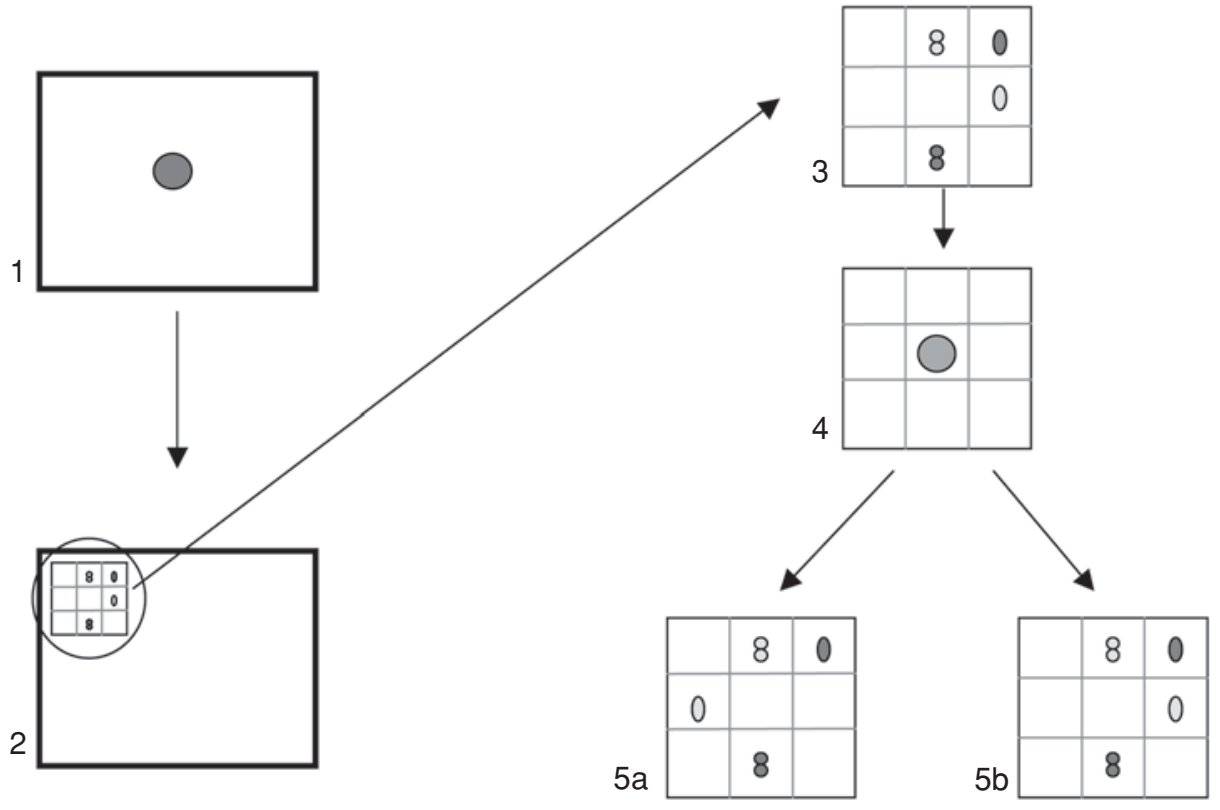

Figure 4. Sequence of events during a testing trial in Experiment 3. (1) The presentation of the start disk. (2,3) An example of a stimulus display as it might be arranged during testing. The ninecell grid was shown at 1 of 32 randomly determined locations on the computer screen with accompanying stimuli. A peapod (vertically stacked filled circles) or a seed (vertical ellipse) shape that was colored either yellow (light coloration) or brown (dark coloration) was located in one of four cells. The target during each trial was the yellow seed (see the text). (4) The presentation of the blue fixation disk and $(5 \mathrm{a}, 5 \mathrm{~b})$ the reappearance of the stimuli in one of two possible configurations for this example. 
had been made (i.e., a correction trial). Each of the final training sessions consisted of 200 trials (counting correction trials). Training lasted between 64 and 82 days.

Testing. Each testing trial began when the start disk appeared on the screen (Figure 4). A peck to the start disk cleared it from the screen, and the four stimuli described during training immediately appeared inside four of the cells of the grid. The target (yellow seed) always appeared in the cell to the north, south, east, or west of the central cell. The other three stimuli could appear in any of the other cells of the grid, with the exception that they might not occupy the central cell or be located in the remaining cell in the row or column in which both the center cell and the target cell were located. The position of the target was balanced across all four locations (north, south, east, or west of the central cell) during each session. The positions of the distractor stimuli were determined randomly, taking into consideration the aforementioned constraints. The result of a peck to any of the distractors was that the stimuli were immediately cleared from the screen and the houselight was turned off; there was a timeout of $30 \mathrm{sec}$, followed by a repetition of the events encountered during the trial- that is, a correction trial. A single peck to the target, in contrast, cleared all four stimuli from the screen, and the blue disk then immediately appeared in the central cell of the grid. A single peck to the blue disk cleared it from the screen, and all four stimuli immediately reappeared in the grid. The target then reappeared in the same cell that it had occupied earlier in the trial (cued trials) or in the cell opposite the center cell and the original location of the target (noncued trials). For example, if the target had been located in the north cell during the first part of the trial, it could be located in the north cell (cued trial) or the south cell (noncued trial) of the grid during the second part of the trial (Figure 4). The position of the target (cued or noncued) was balanced during the session. No more than two cued or noncued trials could occur consecutively during the course of a session. Unlike training, the locations of the three distractor stimuli stayed the same during the trial. A peck to the target resulted in a reward, followed by a 15 -sec ITI. A peck delivered to any of the distractors resulted in the implementation of correction procedures as described previously. Each pigeon encountered 200 trials per session (counting correction trials). One session of testing was conducted per day, and testing continued for 10 days. The percentage of correct trials (trials on which no distractors were selected) was recorded during each session. The time to respond to the target (RT) was recorded during each trial and was calculated as described previously. The data from incorrect or correction trials were not used in the determination or analysis of RTs.

\section{Results and Discussion}

The pigeons' RTs to the target (see Figure 5) when the target was cued (same location), as compared with when the target was not cued (opposite location), appeared to be comparable. To test the reliability of this observation, a repeated measures ANOVA with day and target location (cued or noncued) as factors was performed. The analysis failed to reveal a reliable difference in RTs between cued and noncued trials $[F(1,3)=3.32]$. There also was a reliable effect of day $[F(9,27)=2.42]$, since Fisher least significant difference comparisons revealed that RTs were longer for the first day than during each of the second, third, fourth, and fifth days (all $p \mathrm{~s}<.05$ ). The analysis failed to reveal an interaction between target location and day $[F(9,27)<1]$. The average SOA across all conditions was $427 \mathrm{msec}(S E M=92)$.

The pigeons correctly selected the target during $97.12 \%$ of the cued trials and $96.39 \%$ of the noncued trials. Because of the similarity in performance across both types of trials and because choice for the target was at such a high level, we did not perform further analyses with the choice data.

The results of all three experiments, with different displays and procedures, indicate that pigeons do not exhibit IOR. Rather, the general trend in the present experiments is one of facilitation of responding to cued targets. In Experiment 4 , to try to increase our ability to detect either facilitation or IOR, we used displays similar to those described in Experiment 3, but with two additional potential target locations.

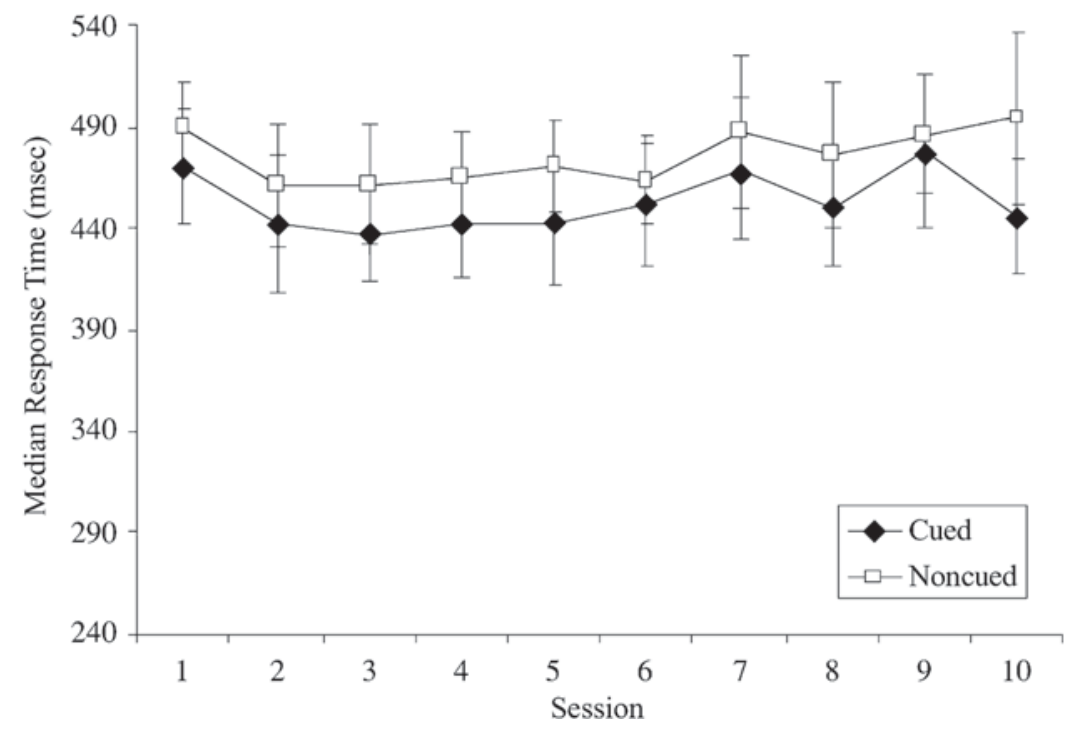

Figure 5. Means of the birds' median response times to cued and noncued targets during testing in Experiment 3. 


\section{EXPERIMENT 4}

In Experiment 4, we used procedures similar to those described in Experiment 3, except that the noncued targets could also be located orthogonal $\left(90^{\circ}\right.$ clockwise or $90^{\circ}$ counterclockwise) to the cued location (as in Pratt, Spalek, \& Bradshaw, 1999, and Snyder \& Kingstone, 2000). The positioning of noncued targets at locations orthogonal to the cued location, in combination with the stimuli used in Experiment 3, might provide a more sensitive method for detecting IOR in pigeons.

Another difference from Experiment 3 was that the distractors were not used during Experiment 4. Our observations indicated that the birds were responding immediately and at a high level to a highly trained target that was surrounded by distractors during Experiment 3 (see Vreven \& Blough, 1998). In addition, recent research with humans has indicated that removal of a scene-like the use of distractors in Experiment 3-during the course of a trial can interfere with IOR. Klein and MacInnes (1999) had human subjects locate a probe stimulus in a region of recent fixation. The subjects showed IOR, but only when the search scene remained present during the trial.

\section{Method}

Animals. The 4 pigeons that were used in Experiment 3 also served in Experiment 4. The RTs for 1 of the 4 birds, however, became excessively large during testing in Experiment 4 (typically, over $5 \mathrm{sec}$ ) and were inconsistent with those of the other birds. This bird was replaced with an experimentally naive bird that had encountered training similar to that received by the 4 birds in Experiment 3 . The pigeons were maintained as described previously.

Testing. The testing trials were similar to those in Experiment 3, except that the distractors were not used during Experiment 4. Also, the target (yellow seed) could reappear in the same cell as the one it had occupied during the first part of the trial (cued), in the opposite cell (noncued), or in one of two orthogonal cells (both noncued). One orthogonal cell was located diagonally to and clockwise from the location of the target during the first part of the trial. The other orthogonal position was located diagonally to and counterclockwise from the position of the target during the first part of the trial. For example, if the seed had been located in the south cell during the first part of the trial, it would be located in the west cell if it occupied the position that was clockwise from and orthogonal to the original position of the target during the second part of the trial. A peck to the target cleared the stimuli from the screen; the reward was delivered, and the ITI procedures followed. Correction trials were not used, since only the target was presented during testing. Each pigeon encountered 200 trials per day, and testing continued for 10 days.

\section{Results}

The pigeons were quicker to respond to a cued target (same location) than to a noncued target positioned clockwise, counterclockwise, or opposite from the cued location (see Figure 6). A repeated measures ANOVA with day and target location as repeated factors was performed, using RT as a dependent measure. The ANOVA revealed a significant effect of target location $[F(3,9)=4.59]$. Planned least squares comparisons revealed that RTs were reliably shorter when the target was located in the same position (cued) than when it moved to the opposite $[t(9)=2.92]$, clockwise $[t(9)=3.39]$, or counterclockwise $[t(9)=2.55]$ positions (noncued) during the course of a trial. The ANOVA failed to reveal a reliable effect of day $[F(9,27)=1.12]$ or an interaction of this factor with target location $[F(27,81)=1.12]$. The average SOA across all conditions was $408 \mathrm{msec}(S E M=82)$.

\section{Discussion}

The positioning of noncued targets at locations orthogonal to the cued location was expected to provide a more sensitive method for detecting IOR in pigeons, as has been shown in some instances in the human literature (Pratt et al., 1999; Snyder \& Kingstone, 2000). In general, the pigeons were faster to respond to a target if the location of the target had been cued than if the location had not been cued. The effect of facilitation occurred irrespective of the location of the noncued target, so that pigeons were faster to return to the cued location regardless of whether the noncued target was in a location orthogonal, clockwise, or counterclockwise from the cued position.

Thus, Experiment 4 revealed strong evidence for a facilitation of responding to cued locations, but no evidence for IOR. Similar effects of response facilitation to a cued target were reported in Experiments 1 and 2. Unlike the first two experiments, however, the stimuli that were used in Experiment 4 were contained in a relatively localized part of the screen. Similar types of displays were also used in Experiment 3, yet the search component required in that experiment may have interfered with facilitated responding to cued targets.

Combined, Experiments 1-4 failed to reveal any evidence for IOR in the pigeon. Although IOR would appear to have wide-ranging implications for a variety of foraging animals, perhaps pigeons and people differ in this domain. Alternatively, perhaps the use of different experimental parameters would reveal IOR in the pigeon or in other nonprimate animals. These issues will be addressed in more detail below.

\section{GENERAL DISCUSSION}

IOR has proven to be a very robust phenomenon in studies of humans, but to our knowledge, tests of its role in the perceptual systems of animals other than primates have not been conducted. We tested for IOR in pigeons, since they show a number of phenomena associated with selective attention in humans (see Shettleworth, 1998, and the introduction to this article). Moreover, if IOR evolved in order to facilitate efficient foraging, as has been suggested, pigeons would be expected to show it. However, although IOR has been readily observed in humans, none of the four experiments reported here revealed any evidence for IOR in pigeons, despite the fact that we used several procedures, that were similar to procedures that are sensitive to IOR when used with people. Instead, in Experiments 1 and 2, pigeons tended to respond reliably more quickly and more consistently (i.e., show response facilitation) to a target location that had been cued and recently pecked 


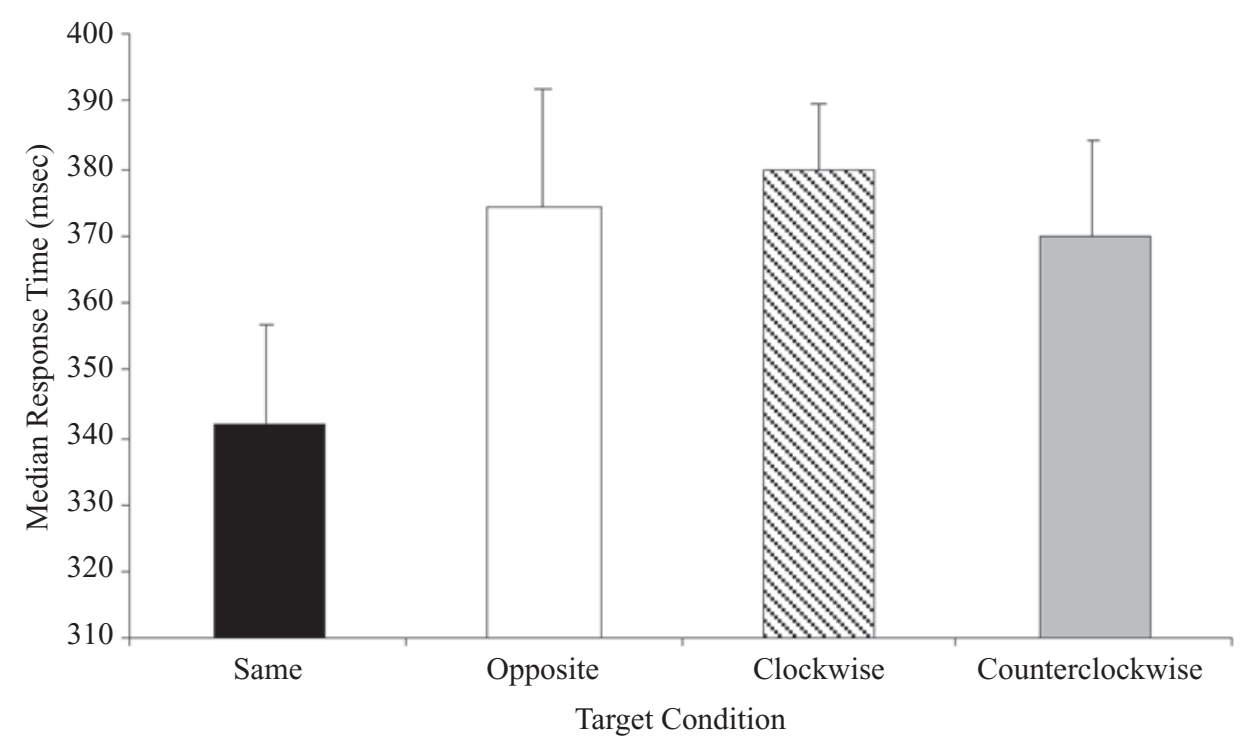

Figure 6. Means of the birds' median response times to cued targets (same location) and noncued targets located opposite, clockwise, and counterclockwise from the cued location across sessions in Experiment 4.

than to other locations. During Experiments 3 and 4, we presented the birds with stimulus displays that were more localized than those used in Experiments 1 and 2, so that the images of the cue and target would tend to fall on the central fovea of the pigeon, a visual region implicated in foraging. As in Experiments 1 and 2, however, the data revealed facilitation of responding to cued targets but no evidence for IOR.

Evidence for IOR-like effects in monkeys has been mixed. Monkeys were slower to respond to a target that had been cued than to a target that had not been cued when they were required to maintain focus on a central fixation stimulus during the course of a trial (Dorris et al., 1999). However, the same monkeys showed facilitation of responding to cued targets when tracking a saccadic target that moved between central fixation and peripheral target sites. The procedures used in the latter paradigm (stimulus-stimulus paradigm) may be more comparable to those used with pigeons in the present study and with which facilitation of responding has been reported for both species.

Why is it that pigeons did not exhibit IOR in these experiments? The findings are consistent with a larger body of literature showing attentional perseveration to cued targets by humans, following relatively short SOAs with similar experimental procedures. Thus, it is possible that one reason for the absence of IOR is that the SOA in the present experiments was too short and that IOR would be found with longer intervals between presentation of the cue and opportunity to peck the target. However, if IOR evolved to serve a foraging function, it should be found within the time needed to make two or three pecks, since only at such short SOAs could it function to redirect pecking away from a just-pecked location (on the basis of the time course of IOR in humans). It remains pos- sible, however, that pigeons would show IOR-like effects with a different set of experimental parameters. Humans show facilitation to cued targets following short SOAs but inhibition (IOR) following longer SOAs (Posner et al., 1985). In the present set of experiments, the times between the onsets of the cue and the target (the SOAs) were not controlled or manipulated. Rather, the interval between the appearance of successive targets depended on the pigeons' behavior. The opportunity for reward during the choice phase of the trial generally ensured that the SOAs were relatively short. The average SOA across all conditions in Experiment 4, for example, was $408 \mathrm{msec}$ $(S E M=82)$, a value well beyond the SOA threshold at which humans often show facilitation (300 msec or less). Nevertheless, the time course for facilitation and, hence, the appearance of IOR (see Klein, 2000, Box 1) could be somewhat delayed in pigeons, as compared with that observed in humans (Posner et al., 1985). Other phenomena, such as primacy and recency effects in memory, are qualitatively similar across humans and pigeons, whereas the time course over which such effects occur is quantitatively different (Wright, Santiago, Sands, Kendrick, \& Cook, 1985). Also, pigeons may not search randomly; instead, they may have strategies. If pigeons employ a systematic search strategy when scanning a localized area for grains, the need for IOR may be diminished.

One possible reason for finding facilitation, rather than inhibition, in the present set of experiments is that responding to the cued location had just been reinforced. The procedures for the pigeons in the present experiments required the animals to respond to the cue before the trial would advance, thereby reinforcing responding to the cued location. In contrast, in many studies of IOR with humans, the subject has been required only to detect the target, rather than respond to it directly. Thus, this proce- 
dural difference could also account for why we were able to detect facilitation, but not IOR, with pigeons. When moving around in space, some animals, such as rats, are predisposed to shift away from locations just visited - that is, they show a win-shift strategy. It would be interesting to see whether a different pattern of results would be observed in tests of IOR for such animals.

One difference between the procedures used to test for IOR in the present study and many of the procedures that have been used to examine IOR with human subjects is the nature of the response that the subjects make to the target. In the present study, the pigeons were required to move their heads through space to respond directly to the target, whereas in many studies that have examined IOR in humans, the subjects have, instead, typically been required to direct their attention (i.e., make a saccade) to the target. The procedures used to examine IOR in humans would appear to map the inhibited location onto retinal coordinates, whereas our procedures would have required inhibition to map onto environmental coordinates. However, much evidence (see Klein, 2000, for a review) has indicated that IOR in humans is coded in an environmental or object-based frame of reference. For example, Maylor and Hockey (1985) used a cued target procedure to investigate IOR in Experiment 3 of their study but required subjects to make a downward saccade to a second fixation point between presentations of the cue and the target. When the target appeared, it could be in a position defined either by the retinal coordinates (position defined by the location of the second fixation point) or by environmental coordinates (position relative to the original fixation stimulus). Notably, the subjects showed IOR only to targets that appeared at the environmental location of the cue. More recent evidence also has indicated that IOR can be "tagged" to scenes and objects in an environment (e.g., Tipper, Weaver, Jerreat, \& Burak, 1994).

Finally, the behavior of human subjects in studies of IOR would appear to be focused on completing the cue-target task, whereas the behavior of pigeons during the course of a trial in the present experiments may have been more variable. The magnitude of the IOR effect in humans - that is, the difference in response latencies to cued and noncued targets - is typically $30 \mathrm{msec}$ (Samuel $\&$ Kat, 2003), and if the time course of IOR were comparable for pigeons, such a modest effect might have been lost during some trials when the pigeons' behavior was not focused on the task. However, the behavior of the pigeons was not so variable as to exclude detecting facilitation. Thus, it seems unlikely that such an account could explain the failure to detect IOR in the present study.

In the four experiments presented here, we used two kinds of procedures - one consistent with the procedures used to investigate IOR in humans and one consistent with the animal foraging literature - to test for IOR in pigeons. Although the results failed to provide any evidence for IOR, the present set of experiments is a substantial start in the investigation of IOR in animals other than primates. The results of the present study could be used as a base for continued explorations of IOR in nonprimate animals. Although IOR is quite robust in humans, revealing itself in a variety of testing procedures, it might be more limited in pigeons, so variations on our procedures or approaches that model other tests that reveal IOR in humans should be explored. The failure to find IOR-like effects in the pigeon and the presence of response perseveration instead would appear to challenge the generality of the hypothesis that IOR facilitates foraging by inhibiting reinspection of previously examined locations. Further research will be required to determine whether this failure applies generally to the pigeon or is linked to some common property(ies) of the tasks we have set for this species.

\section{REFERENCES}

Blough, D. S., \& Blough, P. M. (1997). Form perception and attention in pigeons. Animal Learning \& Behavior, 25, 1-20.

Blough, P. M. (1991). Selective attention and search images in pigeons. Journal of Experimental Psychology: Animal Behavior Processes, 17, 292-298.

Bond, A. B. (1983). Visual search and selection of natural stimuli in the pigeon: The attention threshold hypothesis. Journal of Experimental Psychology: Animal Behavior Processes, 9, 292-306.

Briand, K. A., Larrison, A. L., \& Sereno, A. B. (2000). Inhibition of return in manual and saccadic response systems. Perception \& Psychophysics, 62, 1512-1524.

Castel, A. D., Chasteen, A. L., Scialfa, C. T., \& Pratt, J. (2003). Adult age differences in the time course of inhibition of return. Journals of Gerontology: Psychological Sciences \& Social Sciences, 58B, P256-P259.

Clark, C. C., \& Dukas, R. (2003). The behavioral ecology of a cognitive constraint: Limited attention. Behavioral Ecology, 14, 151-156.

Clohessy, A. B., Posner, M. I., Rothbart, M. K., \& Vecera, S. P. (1991). The development of inhibition of return in early infancy. Journal of Cognitive Neuroscience, 3, 345-350.

Dorris, M. C., Klein, R. M., \& Everling, S. (2002). Contribution of the primate superior colliculus to inhibition of return. Journal of Cognitive Neuroscience, 14, 1256-1263.

Dorris, M. C., Taylor, T. L., Klein, R. M., \& Munoz, D. P. (1999). Influence of previous visual stimulus or saccade on saccadic reaction times in monkey. Journal of Neurophysiology, 81, 2429-2436.

Fischer, M. H., Pratt, J., \& Neggers, S. F. W. (2003). Inhibition of return and manual pointing movements. Perception \& Psychophysics, 65, 379-387.

Francis, B., Green, M., \& Payne, C. (1993). The GLIM system: Statistical software for generalized linear interactive modeling. Oxford: Oxford University Press, Clarendon Press.

Gilchrist, I. D., \& Harvey, M. (2000). Refixation frequency and memory mechanisms in visual search. Current Biology, 10, 1209-1212.

Hartley, A. A., \& Kieley, J. M. (1995). Adult age differences in the inhibition of return of visual attention. Psychology \& Aging, 10, 670-683.

Kelly, D. M., \& CooK, R. G. (2003). Differential effects of visual context on pattern discrimination by pigeons (Columba livia) and humans (Homo sapiens). Journal of Comparative Psychology, 117, 200-208.

Kingstone, A., \& Pratt, J. (1999). Inhibition of return is composed of attentional and oculomotor processes. Perception \& Psychophysics, 61, 1046-1054.

KLEIN, R. [M.] (1988). Inhibitory tagging system facilitates visual search. Nature, 334, 430-431.

KleIn, R. M. (2000). Inhibition of return. Trends in Cognitive Sciences, 4, 138-147.

Klein, R. M., \& MacInnes, W. J. (1999). Inhibition of return is a foraging facilitator in visual search. Psychological Science, 10, 346-352.

Langley, C. M., Riley, D. A., Bond, A. B., \& Goel, N. (1996). Visual search for natural grains in pigeons (Columba livia): Search images and selective attention. Journal of Experimental Psychology: Animal Behavior Processes, 22, 139-151. 
Lupiáñez, J., Milliken, B., Solano, C., Weaver, B., \& Tipper, S. P. (2001). On the strategic modulation of the time course of facilitation and inhibition of return. Quarterly Journal of Experimental Psychology, 54A, 753-773.

MacInNes, W. J., \& KLeIN, R. M. (2003). Inhibition of return biases orienting during the search of complex scenes. Scientific World Journal, 3, 75-86.

MacPherson, A., Klein, R. M., \& Moore, C. M. (2003). Inhibition of return in children and adolescents. Journal of Experimental Child Psychology, 85, 337-351.

MaYlor, E. A., \& Hockey, R. (1985). Inhibitory component of externally controlled covert orienting in visual space. Journal of Experimental Psychology: Human Perception \& Performance, 11, 777787.

McCarley, J. S., Wang, R. F., Kramer, A. F., Irwin, D. E., \& PeterSON, M. S. (2003). How much memory does oculomotor search have? Psychological Science, 14, 422-426.

Müller, H. J., \& VON MüHLENEN, A. (2000). Probing distractor inhibition in visual search: Inhibition of return. Journal of Experimental Psychology: Human Perception \& Performance, 26, 1591-1605.

PosNer, M. I., \& CoHEN, Y. (1984). Components of visual orienting. In H. Bouma \& D. G. Bouwhuis (Eds.), Attention and performance X: Control of language processes (pp. 531-556). Hillsdale, NJ: Erlbaum.

Posner, M. I., Rafal, R. D., Choate, L. S., \& Vaughan, J. (1985). Inhibition of return: Neural basis and function. Cognitive Neuropsychology, 2, 211-228.

Pratt, J., Kingstone, A., \& Khoe, W. (1997). Inhibition of return in location- and identity-based choice decision tasks. Perception \& Psychophysics, 59, 964-971.

Pratt, J., Spalek, T. M., \& Bradshaw, F. (1999). The time to detect targets at inhibited and noninhibited locations: Preliminary evidence for attentional momentum. Journal of Experimental Psychology: Human Perception \& Performance, 25, 730-746.

ReId, P. J., \& Shettleworth, S. J. (1992). Detection of cryptic prey: Search image or search rate? Journal of Experimental Psychology: Animal Behavior Processes, 18, 273-286.
Riley, D. A., \& Roitblat, H. L. (1978). Selective attention and related cognitive processes in pigeons. In S. H. Hulse, H. Fowler, \& W. K. Honig (Eds.), Cognitive processes in animal behavior (pp. 249-276). Hillsdale, NJ: Erlbaum.

SAmuel, A. G., \& Kat, D. (2003). Inhibition of return: A graphical meta-analysis of its time course and an empirical test of its temporal and spatial properties. Psychonomic Bulletin \& Review, 10, 897 906.

Shettleworth, S. J. (1998). Cognition, evolution, and behavior. New York: Oxford University Press.

SNyder, J. J., \& Kingstone, A. (2000). Inhibition of return and visual search: How many separate loci are inhibited? Perception \& Psychophysics, 62, 452-458.

TAKEDA, Y., \& YAGI, A. (2000). Inhibitory tagging in visual search can be found if search stimuli remain visible. Perception \& Psychophysics, 62, 927-934.

TAYLOR, T. L., \& KLEIN, R. M. (2000). Visual and motor effects in inhibition of return. Journal of Experimental Psychology: Human Perception \& Performance, 26, 1639-1656.

Tipper, S. P., Weaver, B., Jerreat, L. M., \& Burak, A. L. (1994). Object-based and environment-based inhibition of return of visual attention. Journal of Experimental Psychology: Human Perception \& Performance, 20, 478-499.

VReven, D., \& Blough, P. M. (1998). Searching for one or many targets: Effects of extended experience on the runs advantage. Journal of Experimental Psychology: Animal Behavior Processes, 24, 98-105.

Wright, A. A., Santiago, H. C., Sands, S. F., Kendrick, D. F., \& CooK, R. G. (1985). Memory processing of serial lists by pigeons, monkeys, and people. Science, 229, 287-289.

Zeigler, H. P., JÄGer, R., \& Palacios, A. G. (1993). Sensorimotor mechanisms and pecking in the pigeon. In H. P. Zeigler \& H.-J. Bischof (Eds.), Vision, brain, and behavior in birds (pp. 265-283). Cambridge, MA: MIT Press.

(Manuscript received May 11, 2004; revision accepted for publication October 5, 2004.) 